\title{
TEORI ELABORASI SEBAGAI STRATEGI PENGORGANISASIAN ISI MATERI PEMBELAJARAN MATEMATIKA
}

\author{
Hermansyah $^{1}$, Irianto Aras $^{2}$ \\ ${ }^{1}$ Jurusan Pendidikan Matematika, Universitas Borneo Tarakan \\ 2 Jurusan Pendidikan Guru Sekolah Dasar, Universitas Borneo Tarakan \\ ${ }^{1}$ h3rmansyah16@gmail.com \\ 2 arasirianto1990@gmail.com
}

\begin{abstract}
Prescriptive theory discusses the determination of learning methods to achieve predetermined learning goals. One aspect that must be considered is how to maintain student retention through rearranging learning materials. The characteristics of mathematics that are taught are arranged hierarchically so that appropriate strategies are needed to organize the content of learning material before it is delivered to students. One organizing strategy is elaboration theory, while the components of elaboration theory are elaborative sequences for the main structure of teaching, the sequence of prerequisites for learning, summary), synthesis, analogy, activating cognitive strategies), and learning controls.
\end{abstract}

Keywords: Learning Strategy, Elaboration Theory.

\begin{abstract}
Abstrak
Teori preskriptif membahas tentang penetapan metode pembelajaran untuk mencapai tujuan pembelajaran yang telah ditetapkan. Salah satu aspek yang harus diperhatikan adalah bagaimana mempertahankan retensi siswa melalui penataan ulang materi pembelajaran. Karakteristik matematika yang diajarkan tersusun secara hierarkis sehingga diperlukan strategi yang tepat untuk mengorganisasi isi materi pembelajaran sebelum disampaikan ke peserta didik. Salah satu strategi pengorganisasian adalah teori elaborasi, adapun komponen teori elaborasi yaitu urutan elaboratif untuk struktur utama pengajaran, urutan prasyarat pembelajaran, rangkuman), sintesa, analogi, pengaktif strategi kognitif), dan kontrol belajar.
\end{abstract}

Kata kunci: Strategi Pembelajaran, Teori Elaborasi.

Salah satu bagian fundamental pada pembelajaran adalah adanya muatan materi yang akan disampaikan, sehingga seorang pengajar dihadapkan pada kondisi bagaimana menyusun materi pembelajaran, hal ini terkait dengan teori pengurutan materi pembelajaran sebelum disampaikan ke peserta didik. Salah satu karakter matematika adalah konsep-konsepnya tersusun secara hirarkis, sehingga untuk memahami suatu konsep ada konsep sebelumnya yang mesti dipahami, untuk itu dalam merancang pembelajaran pertimbangan tentang urutan-urutan materi diperlukan.

Dalam paham kognitivisme masing-masing peserta didik dipandang memiliki struktur kognitif yang berbeda-beda. Struktur kognitif itulah yang menjadi faktor utama yang mempengaruhi kebermaknaan dari perolehan pengetahuan baru (Budiningsih, 2004). Oleh karena itu, dalam pembelajaran diperlukan adanya upaya untuk mengorganisasi isi materi pelajaran serta penataan kondisi pembelajaran agar dapat memudahkan proses asimilasi ke dalam struktur kognitif yang ada. Selain itu, dengan mengorganisasi isi pembelajaran diharapkan peserta didik memiliki retensi terhadap materi pembelajaran dapat bertahan lebih lama, sebagaimana hasil penelitian hasil penelitian Degeng (1997), bahwa mengorganisasi isi pembelajaran terlebih dahulu sebelum disampaikan ke peserta didik dapat memepertahankan retensi peserta didik lebih baik. 
Untuk itu dalam mendesain pembelajaran matematika, strategi pengorganisasian juga diperlukan. Salah satu pengorganisasian isi pembelajaran adalah dengan bertumpu pada teori elaborasi, teori ini dimulai dengan memberikan kerangka isi pembelajaran, kemudian memilih isi bidang studi menjadi bagian-bagian, merincikan tiap bagian, memilah bagian menjadi sub-sub bagian, kemudian merincikan tiap-tiap bagian, begitu seterusnya sampai tingkat kerincian yang dispesifikasi oleh tujuan. Dengan cara seperti ini, maka si-belajar akan selalu mengaitkan antara tiap-tiap sub bagian ke bagian, dan tiap bagian ke konteks yang lebih luas, hal ini tentu menghasilkan retensi yang lebih baik.

\section{METODE PENELITIAN}

Penelitian ini merupakan penelitian studi literatur, yang dilakukan untuk mengkaji referensi tentang teori elaborasi sebagai bagian dari strategi pengorganisasian pembelajaran. Adapun tahapan penelitian yang dilakukan yaitu:

1) Menyusun rencana topik yang akan dikaji.

2) Mencari sumber pustaka relevan dan memilih materi dari berbagai sumber pustaka yang sesuai.

3) Data yang diperoleh dari pengkajian materi digunakan sebagai acuan untuk membuat pembahasan dan kesimpulan.

\section{HASIL DAN PEMBAHASAN}

\section{Strategi Pembelajaran}

Istilah strategi berasal dari Yunani yaitu strategia yang berarti 'ilmu perang' atau 'panglima perang'. Strategi diartikan sebagai suatu seni merancang operasi di dalam peperangan, seperti caracara mengatur posisi atau siasat berperang angkatan darat atau laut. Strategi dapat diartikan pula sebagai suatu keterampilan mengatur suatu kejadian atau hal ikhwal. Sehingga, strategi adalah cara, siasat, atau haluan bertindak yang disusun secara sistematis untuk mencapai tujuan tertentu.

Albus, Turlhow, \& Clapper (2007:3) mengemukakan bahwa strategi pembelajaran adalah suatu set kegiatan sistematis yang digunakan oleh seorang guru yang berisi langkah-langkah yang jelas agar peserta didik mencapai hasil tertentu. Set langkah-langkah yang dibuat harus bisa direplikasi oleh orang lain untuk dipertimbangkan sebagai suatu strategi. Sementara Dick \& Carey (1990) mengatakan bahwa strategi pembelajaran adalah semua komponen materi/paket pengajaran dan prosedur yang digunakan untuk membantu peserta didik dalam mencapai tujuan pengajaran.

Weinstein \& Underwood (1985) mengemukakan "the term learning strategies is used in a very broad sense to identify a number of different competencies that researches and practioners have postulated as neccessary, or helpful, for effective learning and retention of information for later use". Artinya bahwa strategi pembelajaran dipakai dalam arti yang sangat luas untuk mengidentifikasi sejumlah kompetensi yang berbeda oleh peneliti dan praktisi yang telah ditetapkan sebagai hal yang 
perlu, atau membantu, untuk efektifitas belajar dan retensi informasi yang kemudian akan dipergunakan.

Jadi secara umum dapat dikatakan bahwa strategi dalam pembelajaran adalah langkahlangkah perencanaan dalam pembelajaran yang disusun berdasarkan konteks yang ada untuk mencapai tujuan yang telah ditetapkan berdasarkan teori-teori pendukung yang teruji sebelumnya.

Weinstein \& Mayer (1983; Gagne, Briggs, \& Wager, 1992:68; Anderson \& Kratwohl, 2001:83) mengelompokkan ragam dari strategi belajar dalam lima kategori, yaitu rehearsal strategies (strategi pengulangan/latihan), elaboration strategies (strategi elaborasi), organizing strategies (strategi organisasi), comprehension monitoring strategy/metaconitive strategies (strategi metakognitif), dan affective strategies (strategi afektif). Klasifikasi lain tentang strategi pembelajaran, juga dikemukakan oleh Reigeluth (1983) dalam Reigeluth \& Keller (2009) bahwa strategi secara garis besar terbagi atas tiga, yaitu organizational strategies (micro to macro), delivery strategies (media selection and utilization), dan management strategies. Berikut penjelasan masing-masing yang disarikan dari Degeng (2005).

1) Strategi Pengorganisasian (Organizational Strategy) adalah metode untuk mengorganisasi bidang studi yang telah dipilih untuk pembelajaran. "Mengorganisasi mengacu pada suatu tindakan seperti pemilihan isi, pembuatan diagram, format dan lainnya yang setingkat dengan itu. Strategi pembelajaran lebih lanjut dibedakan atas dua, yaitu strategi mikro dan makro. Strategi mikro mengacu kepada metode untuk mengorganisasi isi pembelajaran yang berkisar pada satu konsep, prosedur, atau prinsip, sedangkan strategi makro mengacu kepada metode untuk mengorganisasi isi pembelajaran yang melibatkan lebih dari satu konsep, prosedur, atau prinsip.

2) Strategi pengelolaan (management strategy) merupakan komponen variabel metode yang berurusan dengan bagaimana menata interaksi antara peserta didik dengan variabel-variabel metode pembelajaran lainnya. Strategi ini berkaitan dengan pengambilan keputusan tentang pengorganisasian dan strategi penyampaian mana yang digunakan selama proses pembelajaran. Setidaknya ada tiga klasifikasi penting variabel strategi pengelolaan, yaitu: penjadwalan, pembuatan catatan kemajuan belajar peserta didik, dan motivasi

3) Strategi penyampaian (delivery strategy). Strategi penyampaian isi pembelajaran merupakan komponen variabel metode untuk melaksanakan proses pembelajaran. Setidaknya ada dua fungsi dari strategi ini yaitu menyampaiakan isi pembelajaran pada peserta didik, dan menyediakan informasi atau bahan-bahan yang diperlukan peserta didik untuk menampilkan hasil kerja.

\section{Tinjauan Umum Teori Elaborasi}

Elaborasi (elaboration) berarti "rinci", jika dihubungkan dengan kata perlakuan berarti "merincikan" atau "perincian". Sehingga, teori elaborasi dalam pembelajaran adalah suatu teori tentang structural strategy yang mengacu kepada bagaimana mengurutkan (sequencing) dan mensintetis (synthesizing) isi materi pembelajaran sebelum disampaikan kepada peserta didik. 
Domain pengurutan yang dimaksud adalah pengurutan dari umum ke rinci, dari sederhana ke kompleks, dan atau dari konkret ke abstrak (Reigeluth, 2003). Pengurutan materi pembelajaran dalam teori elaborasi berasal dari pengembangan teori Jerome Brunner melalaui kurikulum spiral dan advance organizer yang dikemukakan oleh David Ausebel. Namun teori elaborasi berbeda pada beberapa hal penting terutama dalam melakukan pengurutan. Urutan elaborasi dimulai dari hal yang paling luas, paling inklusif, dan yang paling penting untuk dijelaskan pertama kali.

Salah satu isu umum tentang pengurutan elaborasi sebagaimana yang diungkapkan Simon (Reigeluth, 2003) bahwa teori elaborasi lebih merupakan teori desain daripada teori deskriptif. Ini berarti bahwa teori elaborasi menekankan pada pencapaian tujuan dan membuat keputusan daripada membuat deskripsi dan kesimpulan. Tujuannya adalah untuk menawarkan panduan tentang cara terbaik untuk mencapai tujuan tertentu, di mana kata "terbaik" ditentukan oleh seperangkat kriteria yang sesuai dengan situasi yang dihadapi. Oleh karena itu, bagian utama dari teori elaborasi adalah metode dan situasi dimana masing-masing metode memungkinkan untuk sampai kepada hasil yang baik. Selain itu, teori elaborasi adalah teori instruksional, yang berarti bahwa tujuannya adalah untuk menawarkan petunjuk tentang metode apa yang digunakan untuk mencapai tujuan tertentu di bawah kondisi tertentu.

Perhatian teori elaborasi dalam pembelajaran menitik-beratkan kepada pemahaman konseptual (apa), pemahan teoritis (mengapa), dan pemahaman prosedur (bagaimana). Struktur pengetahuan konseptual (atau peta konsep ) untuk "memahami apa" dan model kausal struktur pengetahuan teoritis untuk "memahami mengapa". Teori elaborasi (Reigeluth \& Stein, 1983) menawarkan pendekatan holistik untuk melakukan pengurutan materi pembelajaran yang membantu peserta didik dapat belajar lebih bermakna dan lebih termotivasi. Hal ini juga dapat memungkinkan peserta didik untuk memiliki kontrol yang lebih atas beberapa ruang lingkup dan urutan keputusan selama proses pembelajaran. Dengan menata urutan dan mensintesis isi materi pelajaran, peserta didik dapat melihat keterkaitan tentang konsep-konsep yang mereka pelajari.

Secara umum, struktur isi pembelajaran dapat dideskripsikan atas struktur konseptual, struktur prosedural, dan struktur teoritik. Struktur konseptual adalah suatu struktur yang menunjukkan hubungan lebih tinggi lebih rendah di antara konsep-konsep. Struktur konsep memuat konsep-konsep mata pelajaran untuk mencapai kompetensi orientasi konseptual. Teori elaborasi mengakui bahwa berbagai jenis urutan yang diperlukan dalam menata isi pelajaran selalu bergantung terhadap karakteristik isi bidang studi dan tujuan instruksional yang hendak dicapai. Sehingga, kita ditekankan untuk selalu memperhatikan sifat materi yang akan di elaborasi, apakah bersifat konseptual, prosedural, atau teoritis. Selain itu, urutan pengelaborasian mempertimbangkan hirarki belajar, karena analoginya begitu susahnya mengajarkan orang untuk bisa mengendarai sepeda motor tetapi dia tidak tahu mengendarai sepeda. Terkait dengan strategi pengurutan dalam teori elaborasi pengurutan dibedakan atas dua macam, yaitu (Reigeluth, 2003): 
1. Pengurutan topik (topical sequencing): topik diajarkan sampai kedalaman yang ditentukan oleh tujuan atau kompetensi yang diperlukan sebelum pindah ke topik berikutnya.

2. Pengurutan spiral (spiral sequencing): penjelasan melewati beberapa topik, yaitu belajar dasardasar dari satu topik, lalu yang lain, dan kembali mempelajari lebih lanjut tentang masing-masing topik.
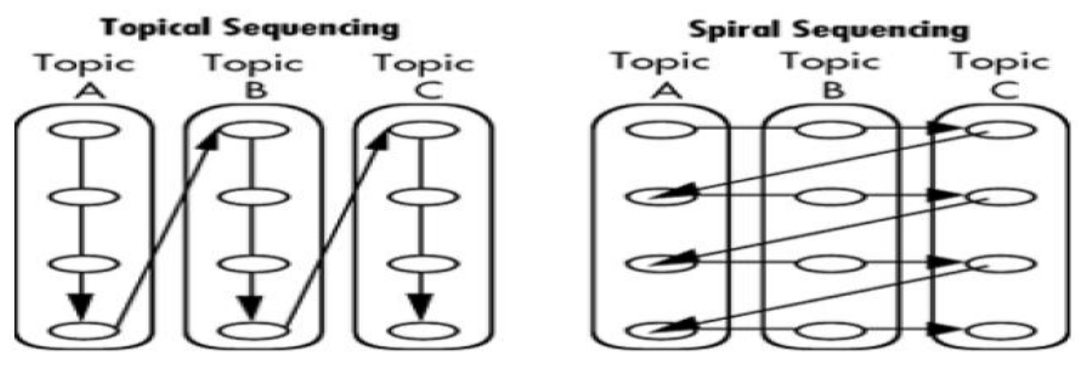

Gambar 1. Topical Sequencing dan Spiral Sequencing

(Sumber: Reigeluth 2003)

Berpijak pada analogi "zoom-lens" (Reigeluth \& Stein, 1983), materi pembelajaran yang diorganisasi dengan teori elaborasi dianalogikan sebagai suatu perbesaran lensa, kerangka (epitome) materi pembelajaran secara keseluruhan disajikan pertama kali ibarat tampilan awal sebuah foto/gambar, kemudian dari epitome itulah dipilih satu sub-bagian untuk dijelaskan, sama halnya dengan memperbesar gambar untuk memperhatikan secara jelas bagian-bagian dari gambar tersebut.

\section{Komponen Strategi Teori Elaborasi}

Dalam melakukan pengurutan materi pembelajaran, teori elaborasi menggunakan tujuh komponen strategi (Reigeluth \& Stein, 1983; Degeng, 1997) yaitu sebagai berikut: 1) urutan elaboratif untuk struktur utama pengajaran, 2) urutan prasyarat pembelajaran, 3) summarizer (rangkuman), 4) syintherizer (sintesa), 5) analogi, 6) cognitive strategy activator (pengaktif strategi kognitif), 7) (learning control) kontrol belajar. Berikut penjelasan masing-masing:

1. Urutan elaboratif adalah urutan dari sederhana-ke-kompleks atau dari umum-ke-rinci, yang memiliki karakteristik khusus dimana mempreskripsikan cara yang amat berbeda dengan cara yang umum digunakan. Urutan elaboratif berbeda dengan cara pengurutan yang lain dalam dua hal, yaitu penyajian isi bidang studi pada tingkat umum mengepitomasi bagian isi yang lebih rinci, dan epitomasi dibuat atas dasar satu tipe struktur bidang studi.

2. Prasyarat pembelajaran didefinisikan sebagai struktur yang menunjukkan konsep-konsep yang harus dipelajari sebelum konsep lain bisa dipelajari. Oleh sebab itu, ia menampilkan hubungan prasyarat belajar untuk suatu konsep.

3. Rangkuman merupakan tinjauan kembali (review) terhadap materi yang telah dipelajari untuk mempertahankan retensi. Fungsi rangkuman untuk memberikan pernyataan singkat mengenai materi yang telah dipelajari dan contoh-contoh acuan yang mudah diingat untuk setiap konsep. Rangkuman yang diberikan di akhir suatu pembelajaran dan hanya merangkum materi yang baru 
dipelajari disebut rangkuman internal (internal summarizer), sedangkan rangkuman semua materi beberapa kali perkuliahan disebut rangkuman eksternal (within set summarizer).

4. Pensintesis (synthesizer) adalah komponen teori elaborasi yang berfungsi untuk menunjukkan kaitan-kaitan diantara konsep-konsep. Pensintesis penting karena akan memberikan sejumlah pengetahuan tentang keterkaiatan antar-konsep, memudahkan pemahaman,meningkatkan kebermaknaan dengan menunjukkan konteks suatu konsep, memberikan pengaruh motivasional, serta meningkatkan retensi.

5. Analogi adalah komponen penting dalam pembelajaran karena mempermudah pemahaman dengan cara membandingkan pengetahuan yang baru dengan pengetahuan yang sudah dikenal peserta didik. Pemakaiannya lebih efektif apabila disampaikan di awal pembelajaran.

6. Pengaktifan strategi kognitif adalah keterampilan-keterampilan belajar yang diperlukan peserta didik untuk mengatur proses-proses internalnya ketika ia belajar, mengingat, dan berpikir yang terdiri atas dua cara: pengadaan melalui perancangan pengajaran dan menyuruh peserta didik menggunakannya. Penggunaan gambar, diagram, mnemonik, analogi, dan parafrase, serta pertanyaan-pertanyaan penuntun dapat memenuhi maksud ini.

7. Konsepsi kontrol belajar mengacu pada kebebasan peserta didik dalam melakukan pilihan dan pengurutan terhadap isi mata pelajaran yang dipelajari (content control), komponen strategi pengajaran yang digunakan (display control), dan strategi kognitif yang ingin digunakannya (conscious cognition control). Berbagai komponen teori elaborasi di atas, seperti: rangkuman, pensitesis, dan analogi, akan memberikan kesempatan kepada peserta didik untuk melakukan kontrol belajar.

\section{Prinsip-Prinsip Model Elaborasi}

Prinsip-prinsip yang mendasari model elaborasi adalah sebagai berikut (Reigeluth \& Stein, 1983; Degeng, 1997):

1) Penyajian kerangka isi. Kerangka isi menunjukkan bagian-bagian utama bidang studi dan hubungan-hubungan utama diantara bagian-bagiannya, hendaknya disajikan pada fase pertama pembelajaran.

2) Elaborasi secara bertahap. Bagian-bagian yang tercakup dalam kerangka isi hendaknya dielaborasi secara bertahap.

3) Bagian terpenting disajikan pertama kali. Pada suatu tahap elaborasi, apapun pertimbang an yang dipakai, bagian terpenting hendaknya dielaborasi pertama kali.

4) Cakupan optimal elaborasi. Kadalaman dan keluasaan tiap-tiap elaborasi hendaknya dilakukan secara optimal.

5) Penyajian pensintesis secara bertahap. Pensintesis hendaknya diberikan setelah setiap kali melakukan elaborasi.

6) Penyajian jenis pensintesis. Jenis pensintesis hendaknya disesuaikan dengan isi materi. 
7) Tahapan pemberian rangkuman. Rangkuman hendaknya diberikan sebelum setiap kali melakukan pensintesis.

\section{Langkah Pengorganisasian Isi Pembelajaran Mengikuti Model Elaborasi}

Adapun tahapan yang perlu dilalui dalam proses pengorganisasian isi pembelajaran menggunakan model elaborasi menurut Degeng (1997: 46) adalah:

1) Menetapkan tipe struktur orientasi

Isi bidang studi perlu dikaji secara cermat agar diketahui tipe struktur orientasinya: apakah konseptual, prosedural ataukah teoritik. Struktur isi konseptual ditekankan pada mengetahui "the what" (the concept) apa dari bidang studi, berbeda dengan struktur prosedural yang menekankan pada "the how" (the procedures), dan struktur teoritik yang menekankan pada "the why" (principles).

2) Memilih dan menata ide ke dalam strukturnya

Isi bidang studi yang berupa konsep-konsep ditata dalam struktur konseptual, isi bidang studi yang berupa langkah-langkah prosedural ditata ke dalam struktur prosedural. Begitu pula dengan isi bidang studi yang berupa prinsip harus ditata dalam struktur teoritik.

3) Menetapkan isi penting yang akan dimasukkan dalam epitome.

Dalam pembuatan epitome, keterkaitan antara isi mutlak ditonjolkan, dalam epitome hanya ada satu tipe isi bidang studi, apakah itu konsep, prosedur, atau hanya prinsip.

4) Mengidentifikasi dan menetapkan struktur pendukung

Semua isi bidang studi yang terkait dan tidak tercakup dalam struktur orientasi, perlu diidentifikasi dan diorganisasi menjadi struktur pendukung. Struktur isi amat diperlukan dalam upaya memberikan informasi yang lebih rinci mengenai isi bidang studi dan sekaligus untuk membantu memudahkan pemahaman isi bidang studi.

5) Menata urutan elaborasi

Setelah semua isi bidang studi penting yang akan dimasukkan dalam epitome ditetapkan, langkah berikutnya adalah menata urutan elaborasi isi yang akan diajarkan. Dalam penataan ini, elaborasi dimulai dari isi yang paling penting. Tingkat kepentingan suatu bidang studi ditentukan oleh sumbangan isi untuk memahami bidang studi yang diajarkan.

6) Merancang epitome, tahapan elaborasi, dan pensintesis.

Isi-isi penting yang telah ditetapkan untuk dimasukkan dalam epitome ditata menjadi struktur konseptual yang bermakna, dalam arti terlihat kaitan-kaitan diantara konsep-konsep tersebut. Berikutnya penahapan elaborasi dikembangkan. mulai dari elaborasi tahap pertama, yang mengelaborasi isi yang ada dalam epitome. Kemudian elaborasi tahap kedua, yang mengelaborasi isi yang ada dalam elaborasi tahap pertama, begitu seterusnya, sampai elaborasi yang paling rinci dan lengkap. 


\section{Langkah Pembelajaran yang diorganisasi dengan Model Elaborasi}

Langkah-langkah pembelajaran yang diorganisasi dengan Model elaborasi.

1) Menyampaikan tujuan pembelajaran.

Dalam kegiatan ini guru menyampaikan tujuan pembelajaran yang hendak dicapai untuk setiap pertemuan. Tujuan pembelajaran pada kurikulum tertera dalam Standar Kompetensi (SK), Kompetesi Dasar (KD), dan Indikator pembelajaran.

2) Menyajikan kerangka isi materi pembelajaran

Setelah menyampaikan tujuan pembelajaran, tahapan selanjutnya adalah menyajikan kerangka isi materi pembelajaran yang memuat seluruh bagian-bagian materi pada satu atau lebih pokok bahasan. Untuk memudahkan peserta didik untuk selalu melihat kerangka isi maka kerangka isi juga harus ada dalam buku peserta didik, tepatnya terdapat dalam bagian depan sebagai peta konsep yang memuat keseluruhan isi buku. Adapun bentuk kerangka isi (epitome) diilustrasikan pada Gambar berikut.

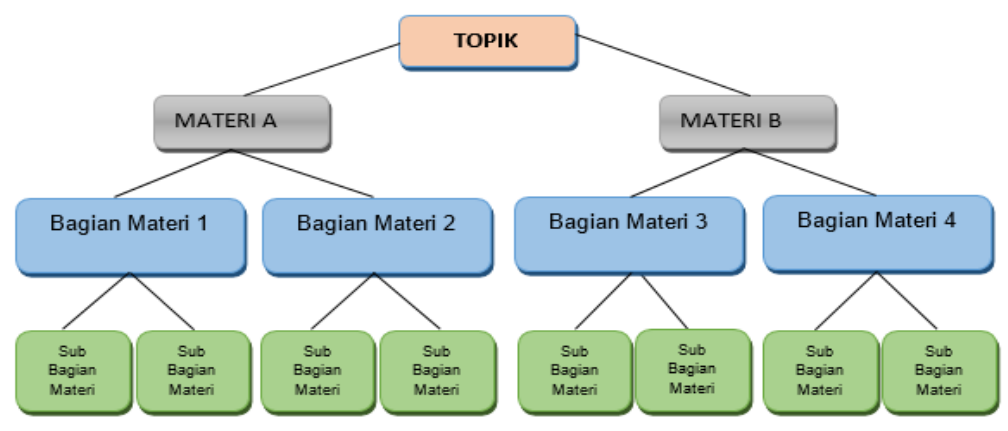

3) Memilih bagian dalam kerangka isi

Gambar 2. Kerangka isi materi pembelajaran

Dari kerangka isi tersebut, kemudian diambil satu bagian yang hendak dijelaskan. Perlu diperhatikan bahwa pemilihan materi pembelajaran pada kerangka isi untuk disajikan pertama kali adalah materi yang menjadi prasyarat dari materi lain dan berkelanjutan untuk beberapa pertemuan setelahnya sampai materi dalam satu pokok bahasan berakhir. Misalnya jika sketsa kerangka isi disajikan sebagai berikut, dan tujuan pembelajaran adalah materi A bagian 1, maka kita menyampaikan ke peserta didik bahwa materi yang akan dibahas untuk pertemuan kali ini adalah materi yang diberi label warna merah seperti berikut. 


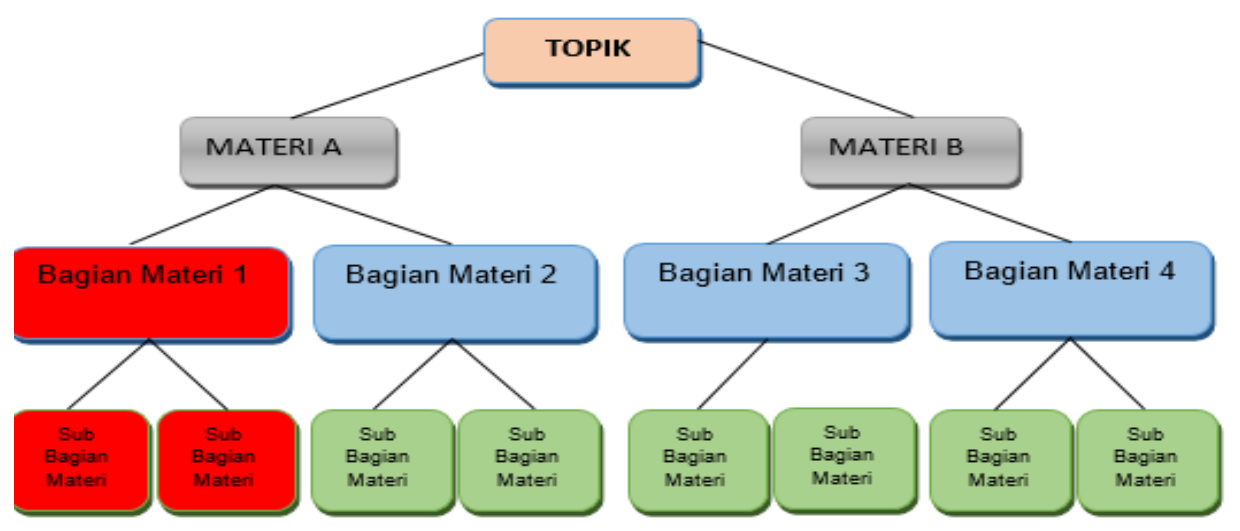

4) Menyajikan materi pembelajaran

Gambar 3. Kerangka isi materi pembelajaran

Setelah dilakukan pemilihan materi pada kerangka isi. Selanjutnya materi disajikan dengan beberapa tahapan-tahapan. Model, pendekatan, dan metode pembelajaran pada tahap ini

5) Memberikan rangkuman

Setelah menyajikan materi pembelajaran, tahap selanjutnya adalah memberikan rangkuman seputar materi yang baru diajarkan. Pemberian rangkuman ini penting agar peserta didik dapat mengetahui apa saja yang baru dipelajarinya, hal ini tentu berguna untuk pembelajaran selanjutnya karena materi matematika tersusun secara hierarkis dalam artian untuk memahami suatu konsep ada konsep sebelumnya yang meski diketahui peserta didik. Pada tahap ini pula dipertimbangkan apakah ada materi lain yang akan dibahas, jika ada maka kembali ke tahapan penyajian kerangka isi, memilih bagian materi yang lain untuk dibahas, menyajikan materi, dan sampai kepada pemberian rangkuman. Hal ini mungkin bersiklus sampai kepada spesifikasi tujuan pembelajaran yang telah ditetapkan sebelumnya untuk setiap pertemuan. Jika tidak maka fase berlanjut ke pemberian lembar kerja peserta didik (LKS).

6) Pemberian Lembar Kerja Peserta didik (LKS)

Setelah mengajarkan suatu materi, tahap selanjutnya adalah menguji coba pemahaman peserta didik terhadap materi yang baru saja dipelajari melalui pemberian masalah. Masalah tersebut direduksi dalam soal dan disajikan dalam bentuk LKS untuk diselesaikan peserta didik. Adapun tahapan-tahapan pemecahan masalah diarahkan ke fase-fase saintifik yang memuat lima kegiatan, yaitu mengamati, menanya, mengumpulkan informasi, menalar, dan menarik kesimpulan. fase-fase tersebut tidak berarti harus termuat dalam setiap soal, namun dengan pengkondisian soal atau masalah yang diberikan.

7) Penyajian Hasil Kerja oleh Peserta didik

Setelah peserta didik menyelesaikan soal pada LKS, beberapa peserta didik menyajikan hasil kerjanya di depan kelas, sementara peserta didik lain memberikan tanggapan. Selanjutnya kegiatan akhir pada fase ini adalah guru memberikan penghargaan ke seluruh peserta didik atas partisipasinya dalam menyelesaikan, berkomentar, atau menyajikan hasil kerjanya. 
8) Penyajian Kembali Kerangka Isi Materi Pembelajaran

Pada tahap akhir guru kembali menyajikan kerangka isi materi pembelajaran, berdasarkan kerangka isi materi pembelajaran tersebut, rangkuman keseluruhan materi pembelajaran yang telah diajarkan juga disampaikan. Selain itu, pemberian kerangka isi di akhir pembelajaran juga ditujukan untuk menyampaikan seputar materi yang akan dibahas pada pertemuan selanjutnya.

\section{KESIMPULAN}

Salah satu karakteristik matematika adalah materinya tersusun secara hierarkis, sehingga dibutuhkan strategi pengorganisasian untuk mengurutkan materi pembelajaran sebelum disampaikan ke siswa. Reigeluth (1983) menempatkan organizational strategies (micro to macro) diantara delivery strategies (media selection and utilization), dan management strategies. Salah satu strategi pengorganisasian adal dengan menggunakan model elaborasi. Dalam melakukan pengurutan materi pembelajaran, teori elaborasi menggunakan tujuh komponen strategi yaitu: urutan elaboratif untuk struktur utama pengajaran, urutan prasyarat pembelajaran, summarizer (rangkuman), syintherizer (sintesa), analogi, cognitive strategy activator (pengaktif strategi kognitif), dan (learning control) kontrol belajar.

Langkah mengorganisasi isi materi pembelajaran menggunakan model elaborasi yaitu menetapkan tipe struktur orientasi, memilih dan menata ide ke dalam strukturnya, menetapkan isi penting yang akan dimasukkan dalam epitome, mengidentifikasi dan menetapkan struktur pendukung, menata urutan elaborasi, merancang epitome, tahapan elaborasi, dan pensintesis. Adapun cara melakukan pembelajaran dengan materinya telah diorganiasi menggunakan model elaborasi yaitu: 1) Menyampaikan tujuan pembelajaran, 2) Menyajikan kerangka isi materi pembelajaran, 3) Memilih bagian dalam kerangka isi, 4) Menyajikan materi pembelajaran, 5) Memberikan rangkuman, 6) Pemberian Lembar Kerja Peserta didik (LKS), 7) Penyajian Hasil Kerja oleh Peserta didik, dan 8) Penyajian Kembali Kerangka Isi Materi Pembelajaran.

\section{DAFTAR PUSTAKA}

Albus, D. Thurlow, M. Clapper, A. T. (2007). Standards-based Instructional Strategies for English Languange Learners with Disabilities (ELLs with Disabilities Report 18). Minneapolis, MN: University of Minneosta National Center on Educational Outcomes.

Budiningsih, Asri. (2004). Belajar dan Pembelajaran. Jakarta: Rineka Cipta.

Degeng, N. S. (1997), Strategi Pembelajaran (Mengorganisasi Isi Pembelajaran dengan Model Elaborasi). Jakarta: IKIP Malang, Biro Penerbitan Ikatan Profesi Teknologi Pendidikan Indonesia.

Degeng, N. S. (2005). Teori Pembelajaran. Modul kuliah teori pembelaran. Malang: Program Pascasarjana Magister Pendidikan IPS Universitas Kanjuruhan Malang.

Degeng, N. S. ( 2013). Ilmu Pembelajaran (Klasifikasi Variabel untuk Pengembangan Teori dan Penelitian). Bandung: Aras Media.

Dick, Walter., \& Carey, L. (1990). The Systematic Design of Instruction. Third Edition. USA: Harper Collins Publisher.

Reigluth, M. Charles. dan Stein, S. Faith. (1983). The Elaboration Theory of Instruction. dalam Charles M. Reigluth (Ed) Instructional Design Theories. Hillsdale, N. J: Lawrence Erbaum Associates, 335-381. 
Reigluth. C. M. (2003). The Elaboration Theory. dalam Ann Kovalchick \& Kara Dawson (Eds). Education \& Technology (An Ensyclopedia). California: ABC-CLEO, Inc.

Reigluth, Charles M. dan Carr-Chellman, Alison A. (2009). Understanding Instructional Theory. dalam Reigluth, Charles M. dan Carr-Chellman, Alison A. Instructional-Design Theories and Models Volume III. New Tork: Routledge.

Reigluth, Charles M. dan Keller, Jhon B. (2009). Understanding Instruction. dalam dalam Reigluth, Charles M. dan Carr-Chellman, Alison A. Instructional-Design Theories and Models Volume III. New Tork: Routledge.

Weinstein, Claire E., \& Mayer, Richard E. (1983). The Teaching of Learning Strategies. Journal CIT. Innovation Abstract; Volume 5 November.

Weinstein, Claire E., dan Vicki L. Underwood.(1985). "Learning strategies: The how of learning”. Thinking and learning skills $1: 241-258$. 